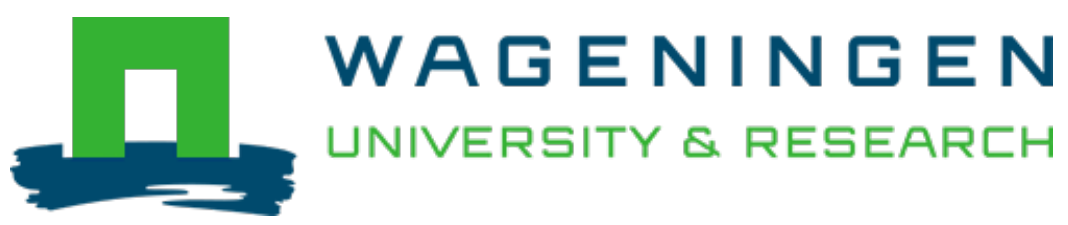

\title{
Making Entrepreneurship Education Available to All : Design Principles for Educational Programs Stimulating an Entrepreneurial Mindset
}

\author{
Entrepreneurship Education and Pedagogy
}

Baggen, Y.; Lans, T.; Gulikers, J.T.M.

https://doi.org/10.1177/2515127420988517

This publication is made publicly available in the institutional repository of Wageningen University and Research, under the terms of article $25 \mathrm{fa}$ of the Dutch Copyright Act, also known as the Amendment Taverne. This has been done with explicit consent by the author.

Article 25 fa states that the author of a short scientific work funded either wholly or partially by Dutch public funds is entitled to make that work publicly available for no consideration following a reasonable period of time after the work was first published, provided that clear reference is made to the source of the first publication of the work.

This publication is distributed under The Association of Universities in the Netherlands (VSNU) 'Article $25 \mathrm{fa}$ implementation' project. In this project research outputs of researchers employed by Dutch Universities that comply with the legal requirements of Article $25 \mathrm{fa}$ of the Dutch Copyright Act are distributed online and free of cost or other barriers in institutional repositories. Research outputs are distributed six months after their first online publication in the original published version and with proper attribution to the source of the original publication.

You are permitted to download and use the publication for personal purposes. All rights remain with the author(s) and / or copyright owner(s) of this work. Any use of the publication or parts of it other than authorised under article $25 \mathrm{fa}$ of the Dutch Copyright act is prohibited. Wageningen University \& Research and the author(s) of this publication shall not be held responsible or liable for any damages resulting from your (re)use of this publication.

For questions regarding the public availability of this publication please contact openscience.library@wur.nl 
Making

Entrepreneurship

Education Available to

All: Design Principles

for Educational

Programs Stimulating

an Entrepreneurial

Mindset
Entrepreneurship Education and Pedagogy

$0(0) \mathrm{I}-28$

(C) The Author(s) 2021

Article reuse guidelines: sagepub.com/journals-permissions DOI: 10.1 I77/25I5I274209885 I7

journals.sagepub.com/home/eex

@SAGE

\title{
Yvette Baggen' (D, Thomas Lans ${ }^{2}$ (D), and Judith Gulikers'
}

\begin{abstract}
Over the past decade, entrepreneurship education (EE) has increasingly been introduced as a school-wide approach to stimulating an entrepreneurial mindset across various educational levels. We refer to this as "wide approaches to EE". Wide approaches to $\mathrm{EE}$ require education programs that go beyond simply defining entrepreneurial competencies (the "what" question) and ask for learning activities that enable the enfolding, cultivation, and development of such competencies (the "how" question). Although important steps have been made with respect to addressing the "how" question, principles to actually design wide EE programs are scarce. Here, we advance the educational practice and research regarding wide EE by deducing design principles for wide EE programs across educational levels based on core theories in the entrepreneurship literature, including experiential learning, social constructivism, and effectuation theory. The II design principles represent the entrepreneurial
\end{abstract}

\footnotetext{
'Wageningen University \& Research, Education and Learning Sciences, Wageningen, The Netherlands

${ }^{2}$ Centre for Expertise in Vocational Education and Training (ecbo), Den Bosch, The Netherlands

Corresponding Author:

Yvette Baggen, Wageningen University \& Research, Education and Learning Sciences, Hollandseweg I, 6706 KN Wageningen, The Netherlands.

Email: yvette.baggen@wur.nl
} 
process, the task, and the context and relationships of wide EE programs, and are discussed in three European cases from different educational levels in order to illustrate how the design principles can be used for understanding wide EE practices. The identified design principles can promote evidence-informed discussion among teachers, curriculum designers, policy-makers, scholars, and others regarding the design, implementation, and investigation of wide EE programs.

\section{Keywords}

educational design principles, entrepreneurial mindset, value creation, entrepreneurship education

Entrepreneurship education (EE) is increasingly used in a wide range of educational contexts and across various educational levels as a school-wide approach for stimulating an entrepreneurial mindset and developing entrepreneurial competence among students. We refer to such education as wide entrepreneurship education ("wide EE"), as opposed to narrow entrepreneurship education, which focuses mainly on starting a business (Lackéus, 2015). The reasons behind integrating entrepreneurship in educational programs is evident: entrepreneurship is a key competence for lifelong learning. Wide entrepreneurship involves the mindset of taking initiative and steering your own learning, development, and career, important aspects given the high level of uncertainty and complexity in today's society (Bacigalupo et al., 2016; Gibb, 2002). Indeed, challenges such as climate change underscore the unprecedented need to effectively deal with uncertainty. Dealing with uncertainty lies at the core of research regarding entrepreneurship, for example research regarding effectuation theory (Grégoire \& Cherchem, 2020). Therefore, entrepreneurship provides an interesting and relevant perspective in terms of determining how we can best prepare young people for their future role in society, in which they will need to deal with a growing number of complex, high-impact societal issues. Each individual should therefore have the opportunity to develop an entrepreneurial mindset via wide EE, thus approaching entrepreneurship as everyday practice (Blenker et al., 2011; Lackéus, 2015, 2020). Such a mindset can provide an entrepreneurial energy - enriching life and empowering individuals to contribute to solving societal issues (Blenker et al., 2011).

Offering wide EE across educational levels and disciplines requires a certain level of agreement with respect to criteria used to design such programs. Therefore, in this conceptual paper we present evidence-informed design principles for wide EE programs and interventions. In practice, these principles may stimulate discussion regarding what wide EE should entail across different 
educational levels between teachers, curriculum designers, policy-makers, and other professionals involved in realizing wide EE courses, programs, and/or learning trajectories. In research, the design principles may serve as a foundation for systematically designing EE interventions and measuring the impact of such interventions, thus allowing for comparisons across contexts and interventions. The design principles therefore serve as a systematic basis for designing, implementing, and investigating wide EE.

The aim of our paper is twofold. First, we build an argument for introducing wide EE, focusing on the entrepreneurial process of value creation. Second, we present educational design principles for designing and implementing wide EE across various educational levels and contexts. We also discuss studies regarding the educational design of EE in general, and wide EE in particular, next to learning theories and value creation theories that can help us understand how entrepreneurs learn and create value. We therefore chose to examine theories that lie at the core of entrepreneurship literature, namely experiential learning and social constructivism (i.e., learning theories) and effectuation theory (i.e., value creation theory). These theories provide a foundation for deducing evidence-informed educational principles for designing wide EE programs, which are illustrated using three European cases derived from different educational levels. We also discuss how the design principles advance our thinking about the design of EE courses and programs for all educational levels, as well as how they stimulate systematic research regarding identifying the effective elements in EE programs in relation to different types of outcomes.

\section{Wide Entrepreneurship Education Focusing on the Entrepreneurial Process}

In his 2015 report for the Organisation for Economic Co-Operation (OECD), Lackéus introduces the distinction between narrow EE and wide EE (Lackéus, 2015). In short, narrow EE prepares individuals to become entrepreneurs, whereas wide EE is directed towards becoming entrepreneurial. Specifically, Lackéus speaks of "learning-by-creating-value" (Lackéus, 2015, p. 11) to depict wide EE in which individuals learn to create value for others. Recently, Lackéus compared EE programs that apply different pedagogical views (Lackéus, 2020). The results of his study indicate that wide EE programshaving value creation at their core - have stronger effects on competence development and motivation of students compared to programs that apply a more classical view on EE, such as new-venture creation. The European Union (EU) acknowledged the importance of this wide approach to entrepreneurship in 2006, when they presented "sense of initiative and entrepreneurship" as one of the key competencies needed by all EU citizens (Bacigalupo et al., 2016). 
The EU therefore positioned entrepreneurship as a broad, transversal competence applicable to both daily living and working life.

Similarly, modern definitions of EE typically include "contents, methods and activities that support the development of motivation, skills and experience, which make it possible to be entrepreneurial, to manage and participate in value-creating processes" (Moberg et al., 2015, p. 14). Different elements from this definition illustrate the wide character of EE. First, this definition emphasizes the learning process underlying entrepreneurship by depicting methods, activities, and the importance of experience. Second, the phrase "to be entrepreneurial" is closely related to the notion of developing an entrepreneurial mindset as part of wide EE (Lackéus, 2015). Third, individuals should be able to "manage" their own career and be self-reliant, which is referred to in works approaching entrepreneurship that reach beyond the narrow focus on simply becoming an entrepreneur (e.g., Bacigalupo et al., 2016; Blenker et al., 2011). Finally, participation in "value-creating processes" is included in this modern definition. Indeed, value creation for others was explicitly included in the EU report by Bacigalupo et al. (2016) in which they defined entrepreneurship as a transversal skill. In the narrow definition of $\mathrm{EE}$, such value creation processes are often about starting a new business (Lackéus, 2015). In wide EE, the value being created can be economic, social, cultural, and/or ecological in nature.

Interest in wide EE is increasing, as is the number of studies regarding this topic (Turner \& Gianiodis, 2018). However, the pedagogical models-the "how" of EE-behind these wide EE programs and interventions are only scarcely studied or described (e.g., Kamovich \& Foss, 2017). Indeed, most studies focus on the impact of EE by studying entrepreneurial intentions or the outcomes that should be addressed in EE programs (Kamovich \& Foss, 2017; Naia et al., 2014). For instance, Naia et al. (2014) reviewed 60 scientific studies involving $\mathrm{EE}$ in higher education in order to identify reported links between the "what" and the "how" of entrepreneurial interventions and evidence of their effectiveness. They found that most studies focused on studying the "what" question (i.e., the outcomes) without describing the EE intervention that led to this result (i.e., the "how", the "why", or "for whom"). More recently, Nabi et al. (2017) reviewed 159 impact studies and compared the results to four didactical models originating from different learning theories. They concluded that most empirical studies focus on outcome measures. Moreover, in their review Kamovich and Foss (2017) noted that most empirical EE studies do not systematically address the "how" question.

Our aim is to move the conversation regarding wide EE from an inputoutput-driven discourse - which often leaves the "how" of EE as a black box-toward a more learning process-oriented approach in which the entrepreneurial process is stimulated by the EE design. From an input-output-driven perspective, we observe that many authors present competency lists as the output of EE (e.g., Fiet, 2001; Man et al., 2002; Morris et al., 2013). 
Although these lists partially overlap, they also have many differences. This makes sense, as competencies are always related to a specific domain (e.g., small business, technology-based entrepreneurship, social entrepreneurship, etc.) and target group (e.g., students, starting entrepreneurs, etc.). However, the large variety of competencies and the context-dependency of competencies make it difficult to use only competencies as the starting point for designing wide EE programs intended for all levels of education and all disciplines. Nevertheless, authors do seem to agree that the competency "identify, test (validate) and exploit opportunities" (Lilleväli \& Täks, 2017, p. 13), which depicts the process underlying wide entrepreneurship, lies at the core of EE (Lilleväli \& Täks, 2017).

Thus, the focus on the entrepreneurial process of value creation now becomes apparent: entrepreneurship is a social process involving the identification, evaluation, and exploitation of opportunities (e.g., Shane \& Venkataraman, 2000), which is often messy, iterative, and uncertain (Sarasvathy, 2001). The competencies required for this process differ depending on the exact nature, context, and target group of the entrepreneurial process of value creation. Although the entrepreneurial process occurs in all entrepreneurial activities and/or courses, the output cannot always be predicted due to the iterative, uncertain, and messy character of the process. Stimulating the entrepreneurial process in education requires an educational approach that sparks the students' curiosity, stimulates them to go through the iterative entrepreneurial process and allows for emergent outcomes (Scardamalia et al., 2012), thus embracing learning surprises rather than focusing on fixed competency outcomes (Lackéus, 2015). We argue that in order to make entrepreneurship available to all, the wide EE practice and research should focus on the "how" question (the design) thereby facilitating the development, implementation, and comparison of wide EE programs across disciplines and educational levels.

\section{What We Already Know Regarding the Design of Wide Entrepreneurship Education}

We are not the first group to elaborate on the "how" question regarding EE programs. Indeed, a search of the published literature revealed two previous studies describing the principles for designing EE. Although these studies provide valuable insights with respect to our design principles, their applicability is somewhat limited.

First, Löbler (2006) formulated ten design principles based on the social constructivist learning theory. He argues that similar to young children, entrepreneurs are creative and are open to new ideas and experiences, asking questions, taking opportunities, and using approaches that do not necessarily reflect what "should be" the preferred style or approach. In this respect, entrepreneurs 
tend to develop their own "roadmap" to success. The transmissive model of education - with standardized and content-driven, business-like teaching - actually forces young children to unlearn their innate entrepreneurial drive. Therefore, Löbler argues that EE should be learning-oriented, rather than teaching-oriented, with a focus on stimulating students to take ownership of their own learning and pursue their own goals. In short, wide EE programs should stimulate the student's autonomy. Löbler formulated principles regarding the various components of educational programs, including the design of learning activities, assessment, and the student and teacher's roles. Because Löbler's principles are well-founded from existing theory and provide valuable insights into entrepreneurial learning, we find Löbler's principles to be informative for designing EE programs. However, the principles are extremely general and prescriptive - e.g., "let students develop their own learning goals" (p. 33) and "do not test students in a classical way" (p. 34) - and do not necessarily align with the notion of creating value with others and for others, as in wide EE. Therefore, Löbler's principles do not fully capture wide EE as we define it, nor do they allow for variations in the EE design to meeting other target groups and/or contexts.

Second, Naia et al. (2014) proposed 13 characteristics of good EE practices. Although the characteristics are both appealing and comprehensible, the authors did not explain how they selected them. In addition, the characteristics seem to differ in their nature; specifically, some characteristics address "what" elements (e.g., individual meta competences), some address "how" elements (e.g., the direct participation of experienced entrepreneurs in training programs), and some characteristics are related to underlying theoretical points (e.g., experiential learning). Moreover, all of the studies used by the authors were from the context of higher education; thus, it is difficult to design wide EE programs that can be applied across educational levels, although their overview does provide valuable input for developing design principles for EE, as discussed below.

Given the limited input from published studies, we reviewed international reports in order to identify additional relevant findings with respect to the design of effective EE. In his report to OECD, Lackéus (2015) used social constructive theory to typify EE. Specifically, Lackéus compared EE to other educational approaches that build upon social constructivist learning, such as problem-based, project-based and service-based learning. Some characteristics are present in most - or even all —of these approaches, including authenticity, real-world action/interaction, artifact creation, and teamwork. Some characteristics are specific to wide EE and include opportunities, iterative experimentation, and the risk of failure; these characteristics therefore offer a good starting point for our design criteria.

Other studies and national reports also support our goal of focusing on the "how" of EE, providing the helpful distinction between education about, for, and through entrepreneurship, showing that different designs can lead to 
different entrepreneurial outcomes for different students (e.g., Fayolle \& Gailly, 2008; Lackéus, 2015; Moberg et al., 2015). In education about entrepreneurship, relevant theories and models are explained. Students have a relatively low level of autonomy and largely follow the standardized program taught by the teacher (Moberg et al., 2015). In education through entrepreneurship, students experience the rather messy and iterative entrepreneurial process. Students learn through active participation and experiential learning, and educational activities stimulate students to participate in the entrepreneurial process. Thus, the learning process - rather than the content - is a key factor in designing the education; as a result, learning can differ between students, allowing for learning surprises to occur (e.g., Scardamalia et al., 2012). The teacher assumes the role of the coach or facilitator in the learning process (Moberg et al., 2015). Finally, education for entrepreneurship combines teaching about entrepreneurship and teaching through entrepreneurship. In discussing this combination, Moberg et al. (2015) make a distinction between the instrumental approach and the entrepreneurial method approach. In the instrumental approach, education is based on entrepreneurship theories, and students have a low level of autonomy over their learning process. In the entrepreneurial method approach, education builds upon the students' experiences and interests such that the students have a relatively high level of autonomy over their learning process. Such education often focuses on non-cognitive outcomes such as the entrepreneurial process, mindset, and the undertaking of entrepreneurial activities.

Different didactic considerations can be made for different target groups. In Denmark, for example, relationships between the learning outcomes of EE and the three didactic approaches discussed above were systematically monitored and evaluated by Moberg et al. (2015). In primary and secondary education, education through entrepreneurship generally has the most positive effect on the students' entrepreneurial skills, resulting in students who are proactive, committed, and enjoy school. Here, the role of the teacher is crucial, as students who perceive their teacher to be a good coach of the entrepreneurial process often perform better. In higher education, education for entrepreneurship - with increasing autonomy and using the students' goals and interest as a starting point - has more of an impact than education about entrepreneurship; thus, students develop more confidence in their capabilities with respect to their financial knowledge, planning, usage of resources, dealing with ambiguity, and creativity. Furthermore, these students are more likely to initiate entrepreneurial activities. The findings by Moberg et al. (2015) are consistent with Lackéus' notion (Lackéus, 2015) that wide EE should start at a young age with education through entrepreneurship, followed by education for entrepreneurship. Thereafter, students who are primarily interested in starting their own business could then engage in education about entrepreneurship.

Taken together, we find that previous studies do not sufficiently discuss the didactics of wide EE programs. At the same time, we find that wide EE 
programs are relevant for students across educational levels and contexts, although differing in their design. In this respect, we have the impression that practice is ahead of scientific research (Lans et al., 2018); indeed, wide EE programs are being applied in several countries, and fortunately the impact of some of these programs is being evaluated, for example by Moberg and colleagues in Denmark. Reports regarding these wide EE programs provide valuable insights with respect to design principles. However, a sound theoretical foundation is essential in order to formulate strong design principles for wide EE. Therefore, in the next section we identify the key criteria for our framework of design principles by delving deeper into the entrepreneurial learning and value creation process. Understanding the nature of entrepreneurial learning and the entrepreneurial process will help us design education that can foster these processes.

\section{Conceptual Foundation for the Design Principles}

Both learning and creating new value are the core of entrepreneurship (Lackéus, 2015). To fully understand the entrepreneurial learning and value creation process, we selected theoretical approaches that form the core of these two aspects, namely experiential learning theory and effectuation theory. These two theories are discussed below, including implications with respect to the design of wide EE programs. Both the key take-away messages and the critiques regarding the theories are discussed and then dealt with additional, complementary theoretical perspectives.

\section{Experiential Learning Theory and Social Constructivism}

Publications regarding entrepreneurship often refer to Kolb's experiential learning theory (ELT). Indeed, experiential learning has also been used recently to design interventions (e.g., Cohen et al., 2020). Experiential learning is an adult learning theory that emphasizes that learning requires concrete, direct experience with real-life, authentic problems. Learning comes from creating knowledge based on these experiences, rather than from instruction (Bergsteiner et al., 2010). This learning involves personal decision-making processes in a specific context, including situations in which the individual experiences conflicts, unexpected events, and disruptions (Kolb \& Kolb, 2005, 2012). Cope and Watts (2000) investigated the effect of these critical incidents by interviewing entrepreneurs and found that these disruptive moments were critically important to the entrepreneur's personal and economic development.

In addition to learning by authentic, complex experiences, ELT also emphasizes the importance of active experimentation and reflection. Specifically, Garavan and O'Cinneide (1994) used Kolb's theory to identify how entrepreneurs learn and found that entrepreneurs use both divergent and convergent 
thinking processes, as both processes are critical for the entrepreneurial process; problem-finding (i.e., identifying opportunities) requires experience, out-of-thebox thinking, and experimentation, whereas problem-solving (i.e., testing and exploiting opportunities) requires reflection and decision-making. Thus, based on ELT, a successful entrepreneur requires experiencing real-life situations, active experimentation, and reflection in an iterative, chaotic learning process in which the risk of failure and unexpected events are always possible. This process and the iterative perspective fit nicely with the definition of wide EE.

Although Kolb's theory on experiential learning is often cited, it has also been criticized for its theoretical foundation and limited attention to context (e.g., Bergsteiner et al., 2010; Morris, 2019; Schenck \& Cruickshank, 2015). Entrepreneurial learning cannot be understood outside of the social context, as entrepreneurial learning is rarely an individual process but involves numerous actions and decisions that are informed by, and enacted with, others (Tynjälä, 2013). For instance, in his recent systematic review Morris (2019) elaborates on the concrete experiences that ELT should entail in order to foster learning. Specifically, ELT should include contextually rich experiences and conceptualizations, critical reflections, and pragmatic active experimentations. ELT has been expanded even further by social constructivist learning theories, which place additional emphasis on the roles of the social, situational, cultural, and historical contexts in which the learning occurs. In addition, design characteristics for EE (see above; see also Lackéus, 2015; Löbler, 2006; Naia et al., 2014) are based on social constructivism, emphasizing the importance of: $i$ ) working in heterogeneous, multidisciplinary teams, $i i$ ) working with, and creating value for, external stakeholders, iii) working in a cultural context, and $i v$ ) the involvement of experienced entrepreneurs as role models during the learning process.

In his review, Morris (2019) raises another important issue with respect to using ELT for designing education, noting that the iterative, chaotic, experimenting, and reflective learning process is complex. Although this learning process does reflect the entrepreneurial process, it requires further translation to education, thus raising the question of how experiential learning can be stimulated by wide EE, and how teachers can facilitate this learning. Schenck and Cruickshank (2015) attempted to advance the theoretical foundation of ELT, describing in their Co-Constructed Developmental Teaching Theory (CCDTT) how this complex learning can be facilitated in education. Their model elaborates upon the iterative, interactive experiential learning process by showing how individuals go through different cycles of learning over time. In these learning cycles, individuals deal with increasing complexity and autonomy, and are supported to some extent by teachers and/or others. The learning cycles describe students' active involvement in activities, alternating with moments of pause, reflection, critical questioning, and feedback from others, as well as the assimilation of new practices in order to secure and sustain their learning (see Schenck \& Cruickshank, 2015, p. 84). 
In addition, CCDTT provides ideas for dealing with progressively increasing complexity and autonomy. The model illustrates how the complexity of activities increases over time, just as the student's autonomy increases over time, suggesting that others (e.g., the teacher, external stakeholders, and/or role models) play a different role in the learning process. Learning to navigate the challenges of life lies the core of what it means to have an entrepreneurial mindset (e.g., Bacigalupo et al., 2016; Blenker et al., 2011).

The learning process elaborated in CCDTT is reminiscent of the multiple rounds of prototyping described in design thinking, a process that is also often linked to describing how entrepreneurs learn in the entrepreneurial process (Rasmussen et al., 2015). The design process consists of several rapid cycles of identifying opportunities, prototyping, and testing with stakeholders (Rasmussen et al., 2015; Smit, 2018), and is similar to the entrepreneurial process of identifying, evaluating, and exploring opportunities (Shane \& Venkataraman, 2000). Whereas CCDTT mainly elaborates the experiential learning process in educational contexts, including the role of the teacher and the students' autonomy, design thinking offers insights into the entrepreneurial, value creation process. Together, both CCDTT and design thinking provide guidelines for how the entrepreneurial process can be operationalized in wide EE.

\section{Effectuation Theory}

Sarasvathy (2001) provides new insights into how entrepreneurs think and make decisions in the entrepreneurial process, particularly in situations characterized by uncertainty (Grégoire \& Cherchem, 2020). Sarasvathy introduces effectuation in a conceptual article in which she contrasts effectuation with causation in relation to entrepreneurs' decision-making logic. With causation, the emphasis is on prediction, whereas effectuation is directed towards controlling and shaping the unpredictable future based on the resources at hand (Kitching \& Rouse, 2020). Dew et al. (2009) found that expert entrepreneurs tend to use effectual thinking, whereas novice entrepreneurs usually attempt to tackle problems using causal thinking and textbook knowledge. Effectuation theory - as a value creation theory - gives new insights into the way in which entrepreneurs tackle the entrepreneurial process in order to create value. Therefore, this theory offers guidelines regarding the educational design that should be covered by $\mathrm{EE}$ programs.

The following four principles lie at the core of effectual thinking: (1) controlling an unpredictable future, (2) affordable loss, (3) strategic alliances, and (4) exploitation of contingencies (Kitching \& Rouse, 2020; Sarasvathy, 2001). Regarding the first principle, rather than attempting to predict an unpredictable future by formulating fixed goals and then attempting to realize those goals (causation), entrepreneurs typically strive to control and steer their future 
using what they currently have (Who am I? What do I know? Who do I know?) to create new value (effectuation). Causation suggests a more linear process for reaching a goal, whereas effectuation suggests a more iterative, non-linear way of learning (Read \& Sarasvathy, 2005; Sarasvathy, 2001). Thus, entrepreneurs tend to focus on the resources and actions that they can control, rather than focusing on what they should do in order to reach a particular pre-specified goal, as this is often out of their control (Read \& Sarasvathy, 2005). This does not necessarily mean that causal thinking plays no role in entrepreneurial decisionmaking. For example, it may be wise to use causational thinking when decisionmaking strongly depends on substantive expertise. In wide EE, these two approaches to decision-making can complement each other, depending on the context, goal, and/or target group (Brettel et al., 2014; Perry et al., 2012). Similarly, prior knowledge and experience are important factors for explaining why some entrepreneurs discover opportunities but others do not. For instance, Shane (2000) found that individuals with a particular education and knowledge background are more likely to identify opportunities in response to technological changes that are related to their specific area of expertise. Although applied from a different (i.e., theoretical) angle, this research illustrates how having disciplinary, domain-specific knowledge and experience ("What do I know?") may facilitate the entrepreneurial process. In the second principle (affordable loss), entrepreneurs tend to take calculated risks and attempt to create value by experimenting as much as possible with the ideas and opportunities that have the highest likelihood of yielding a return and low, affordable losses. A study by Dew et al. (2009) illustrate this principle by showing that experienced entrepreneurs tend to minimize the disadvantages resulting from their actions, rather than focusing on the actions that may have the highest returns. With the third principle, entrepreneurs tend to collaborate with strategic partners who would actually be perceived as competitors, at least from a more traditional, causation point of view. This principle illustrates the importance of collaborating with a variety of stakeholders during the entrepreneurial process, as well as the importance of being open to collaborating across the boundaries of your own discipline and/or perspective (Lans et al., 2018; Naia et al., 2014). Finally, with the fourth principle (exploitation of contingencies), new contingencies are used either as opportunities or as input in the entrepreneurial process. These contingencies may replace other goals, in which case the entrepreneurial process becomes more fluent and chaotic by both responding to and integrating changes that occur over time (Kitching \& Rouse, 2020; Read \& Sarasvathy, 2005).

These four principles - considering both causal and effectual thinking and decision-making, allowing for the identification and exploitation of opportunities by experimenting and taking calculated risks, involving various collaborations and stakeholders, and incorporating the unexpected when confronted with challenges and complexity - guide the design criteria for wide EE programs. Causal thinking facilitates the exploitation of knowledge, whereas effectual 
thinking facilitates the exploitation of contingencies. In addition, effectuation theory touches upon the importance of asking "Who am I?" Research has shown that entrepreneurs develop an entrepreneurial identity during their entrepreneurial learning journey (Lundqvist et al., 2015; Rae, 2006). This entrepreneurial identity is interwoven with the entrepreneur's personal motives, values, and intentions (Bernal \& Liñán, 2018), which increasingly become focused on not only creating economic value, but also creating value for a more sustainable, better world (see for example, Schaltegger \& Wagner, 2011). Whereas research on effectuation originally focused on understanding how experienced entrepreneurs create value by starting a business, Obrecht (2016) shows that the theory can also be applied to sustainable entrepreneurship and the development of entrepreneurial identity. To support the development of an entrepreneurial identity in students, effectuation theory tells us that wide EE should pay attention to the students' personal motives, values, and intentions (Lans et al., 2014; Ploum et al., 2017). This is consistent with design principles of Löbler (2006) discussed above, which focus on encouraging students to steer their own learning by building on their own interests and goals. An important point related to identity development is that students engaged in wide EE should be encouraged to create value for others that may be economic, social, cultural, and/or ecological in nature (Obrecht, 2016). In this respect, role models and storytelling may help students think about questions such as "Who am I?", "What do I have?", and "What kind of value do I want to create, and for whom?", which can help them develop their entrepreneurial identity (Donnellon et al., 2014). Identity development also links to one of the design principles discussed by Naia et al. (2014), namely involving experienced entrepreneurs who can function as role models in EE.

Consistent with the experiential learning theory, Kitching and Rouse (2020) argue that the effectuation theory should include a social context dimension, as effectual decision-making logic is not sufficient for understanding the entrepreneurial process. Indeed, they argue that social structures (e.g., gender, ethnicity, and socio-economic class), cultural structures (i.e., social norms), and agency (i.e., the entrepreneur himself/herself) interact and jointly shape the process of value creation. Building on, using, and interacting with social and cultural networks, values, and norms are key for the entrepreneur. In the context of wide $\mathrm{EE}$, choices can be made with respect to the social and cultural context in which learning occurs, thereby affecting the amount of uncertainty, creating and/or restricting possibilities, and affecting the number and types of collaborations in educational programs. Educators may consider the complexity of the context in which they want their students to work, which can range from the local, familiar level to the national, international, or even systemic level, thereby allowing for dynamic changes in the social and cultural structures that the students must take into account when creating value. 


\section{Towards Evidence-Informed Design Principles for Wide EE}

The main purpose of the design principles is to stimulate discussion among educators regarding questions such as: How did we design our current EE program, in terms of the design principles?; What variety did we include in the educational program, and why?; Is this aligned with our learning goals?; And can we-based on the design principles - further improve our educational program? The design principles are formulated in such a way that educators can use them as extremes in a continuum, clearly present in the educational setting, depending on the educational program's learning goals and target group. This allows educators to systematically reflect on the amount of complexity and uncertainty they would like to include in their EE program. In addition to being useful for educators, the principles also allow researchers to systematically report the results of their empirical studies in EE.

In formulating the design principles, we found that certain characteristics seem to be a prerequisite for EE programs, whereas other characteristics can vary across educational settings and may or may not be included. With respect to the required characteristics, wide EE always includes:

1. The entrepreneurial process of $i$ ) opportunity identification, ii) opportunity evaluation, and iii) opportunity exploration (i.e., getting into action) - either in that order or iteratively;

2. Authentic, actual tasks with several solutions; and

3. The creation of new value for others.

In addition to these three prerequisite design principles, we also identified eleven principles that can differ across educational settings and fall within the following three categories: (1) the entrepreneurial process, (2) the task, and (3) the context and relationships. Because the presence of specific design principles can differ among different educational programs, they can be perceived as representing the ends of a continuum, being present to some extent in wide $\mathrm{EE}$ programs. A brief explanation of the principles and the extremes on the continuum is given in Table 1, facilitating discussion among educators regarding the practical application of these principles. To illustrate how the model and its principles work, we present three exemplary cases below.

\section{Three Illustrative Cases: Holiday Island, Student Company, and Climate-KIC}

Below, we introduce and describe three Europe-based examples of wide EE targeted to three specific groups, namely primary education, vocational education, and higher education. The text provides a brief introduction to the course, and Table 2 shows how the three examples relate to the 11 design principles. 


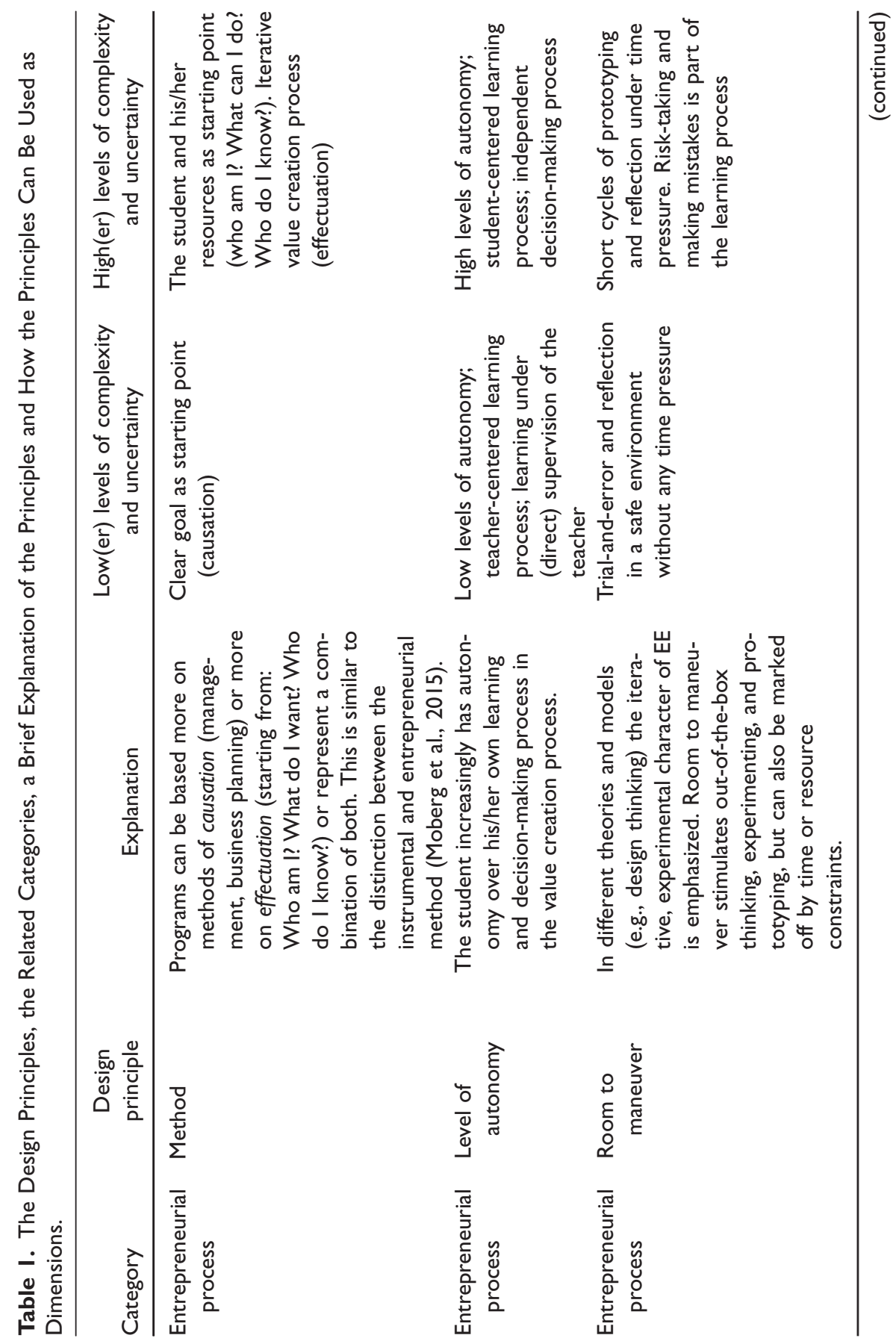




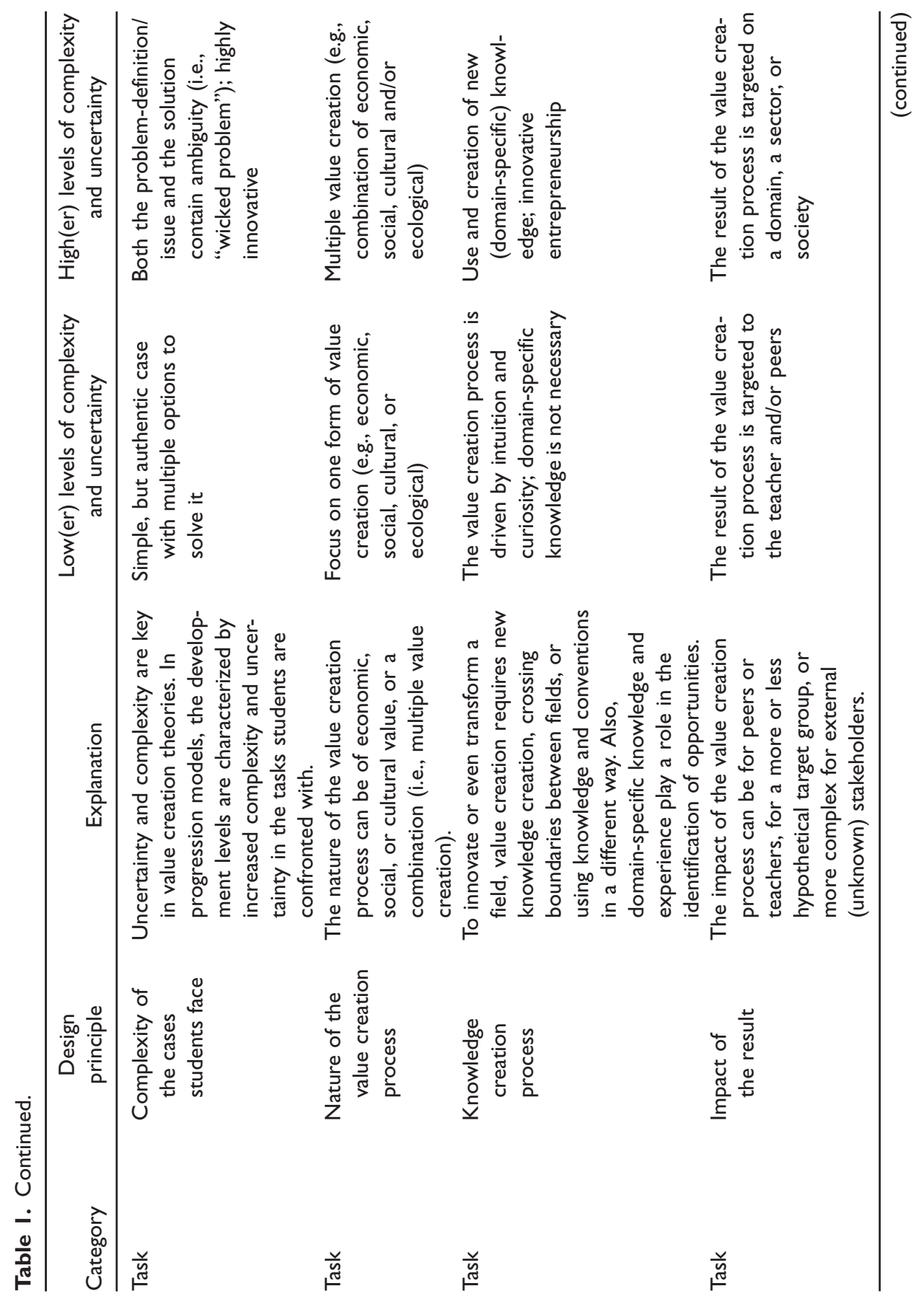




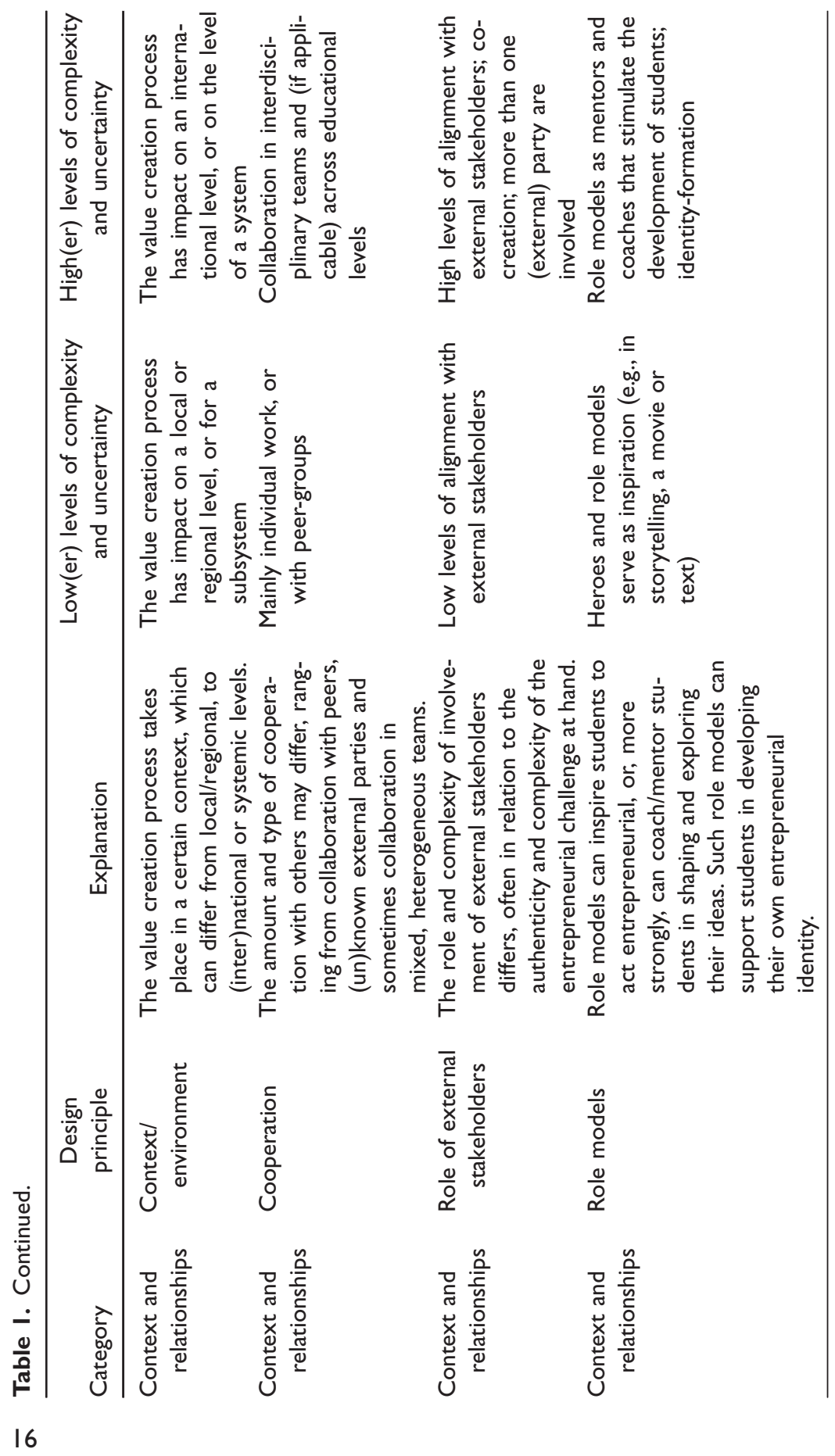


The first case, Holiday Island, is a case taken from Young Enterprise in the Netherlands regarding primary education. The Holiday Island program is for entrepreneurial, research-minded students 8-10 years of age. The program provides an explicitly wide view on entrepreneurship, and the assignment is to design a holiday island that should be commercially viable. During four halfday sessions, the students focus on two key learning outcomes, namely decisionmaking and taking responsibility for their own actions.

The second example case is the Student Company program, which many schools target to students 15-18 years of age. These programs are offered by JA Europe (a non-profit in Europe dedicated to preparing young people for employment and entrepreneurship), among others. In this program, students run their own venture for one academic school year, during which they assign roles, determine their target group, develop ideas regarding their product, write a business plan, acquire seed money, and create a financial overview. This program allows the students to experience the entrepreneurial process of starting a new venture, helping them develop a "can-do" mentality and important skills such as creative thinking, problem-solving, negotiation, and decision-making. In the program, students also have the opportunity to compete with other student companies to become the "Student Company of the Year".

The third case, namely the Climate-KIC Master School, is from higher education. Climate-KIC Master School is part of the European Knowledge and Innovation Communities (KIC), which is supported by the European Institute of Innovation and Technology, providing a series of education programs for students, postgraduates, and professionals. The Climate-KIC Master School is designed to connect sustainable entrepreneurship with climate-oriented degree programs at specific universities. The intensive, 2-year program consist of several courses, a 4-week entrepreneurial summer school known as the "journey", a mobility program including field work and an internship, and several extracurricular workshops known as the "sparks". The program is designed to address the following key learning outcomes: (1) discovering how the latest scientific data regarding climate change is transformed into new products and/or services; (2) examining market drivers of climate innovation, including policy, legal, and financial incentives or constraints, and (3) exploring the potential for launching a start-up business venture.

Although it may feel comparing apples and oranges, the design principles reflect the (often unconscious) educational design choices that are made within the programs as well as the sense of progression in wide EE that one would expect between programs (i.e., moving from primary education to vocational education to higher education). The three cases discussed above illustrate how specific design principles can be applied to learning programs geared to extremely young, novice students (in primary education), more advanced students (in vocational education), and highly experienced students (at the university level). Not surprisingly, the program that targets experienced students incorporates 


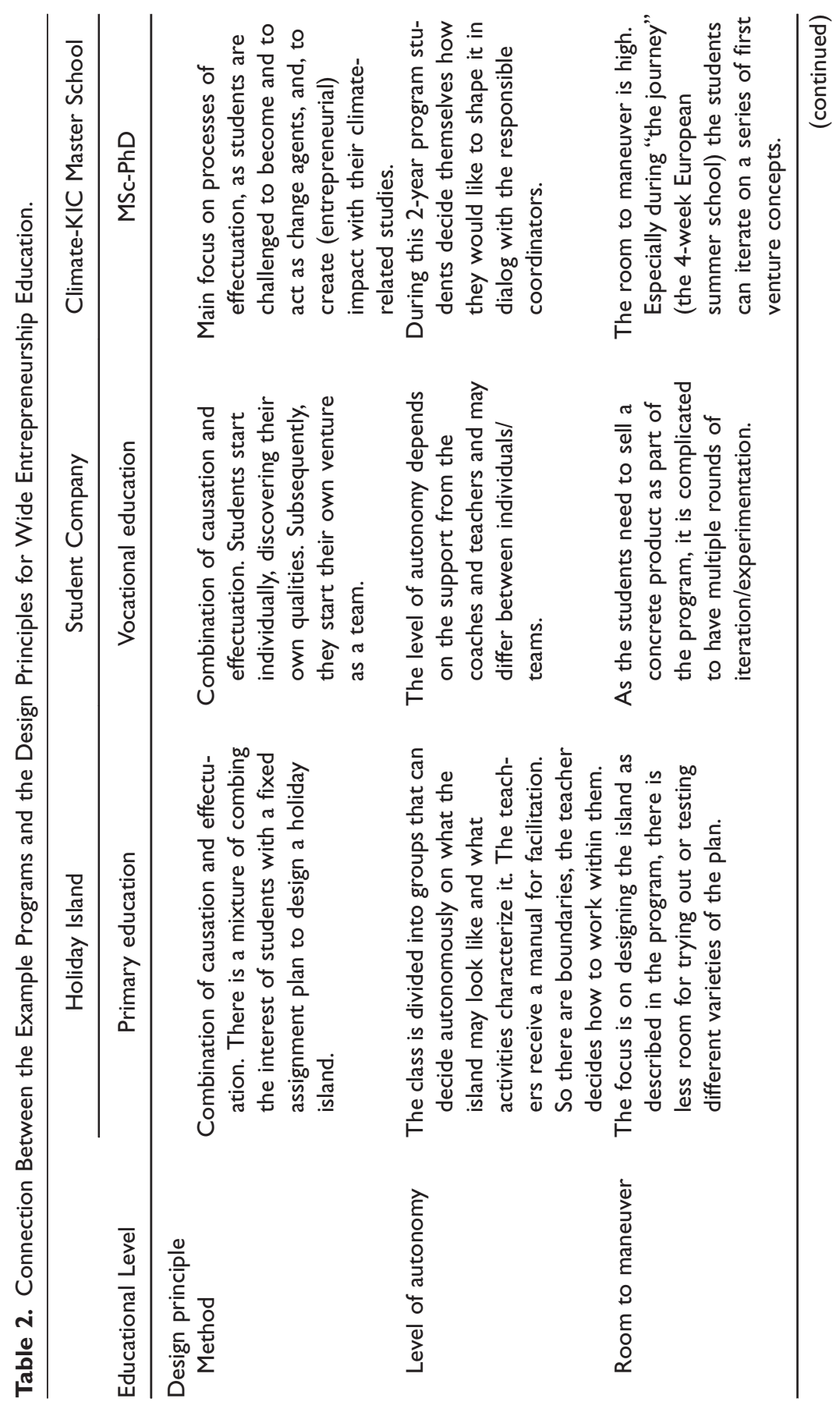




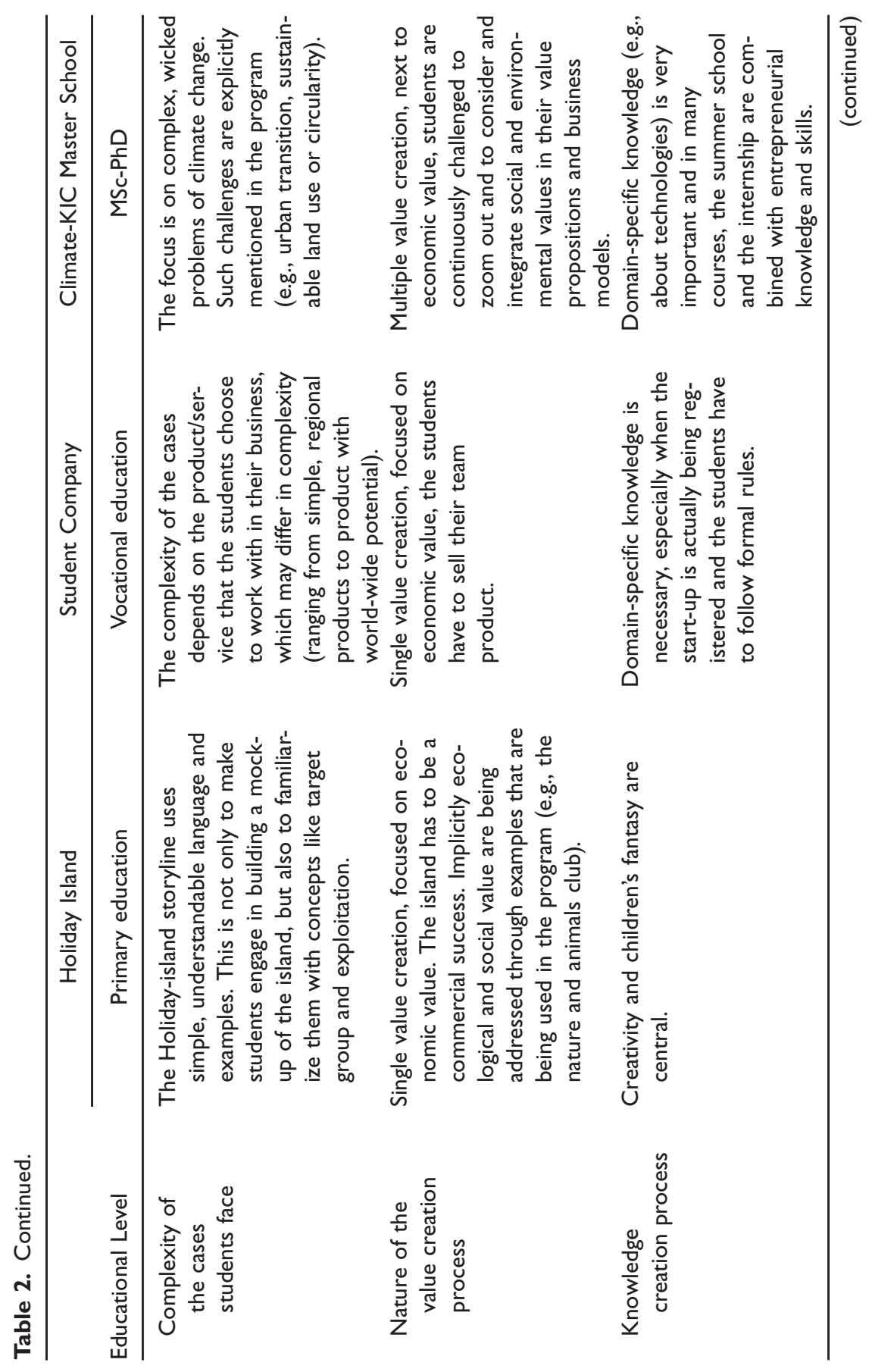




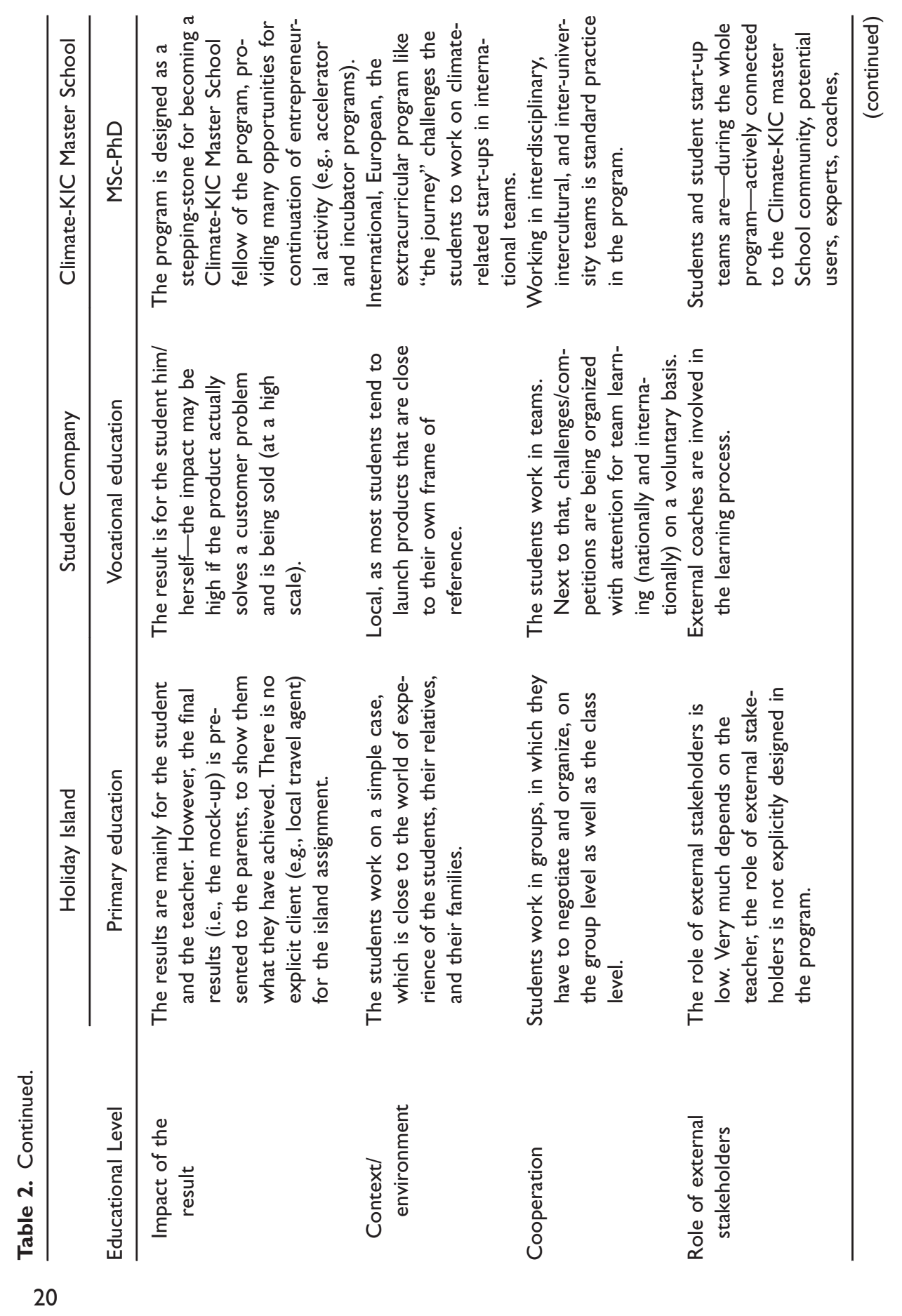




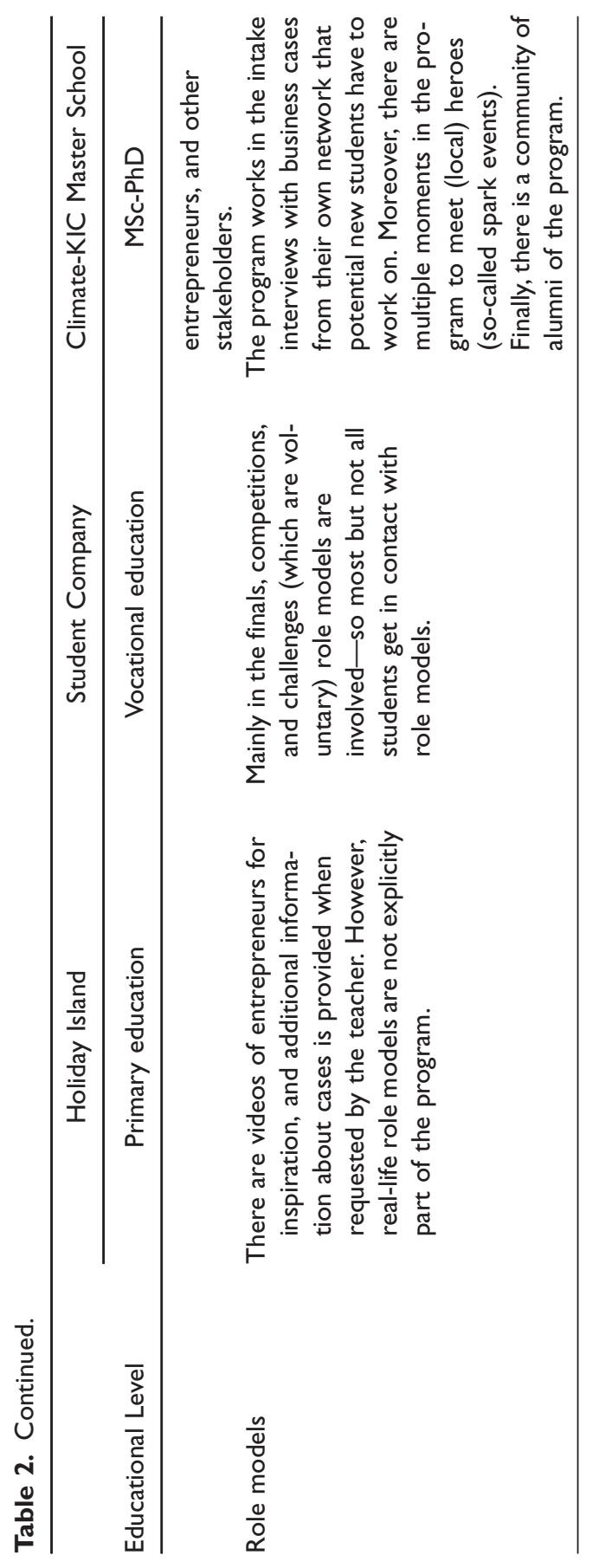


much higher levels of uncertainty and complexity compared to the other programs. The design principles can therefore help reflect on the program and consider the programs fit in the context of wide EE. For instance, in the Holiday Island case educators might consider explicitly addressing ecological and social value, a notion currently addressed implicitly in the program. In addition, the Student Company program has considerable room for increasing the level of complexity and uncertainty, including for example the level of autonomy, the complexity of the cases with which the students work, the impact of the result, and the involvement of role models in the entrepreneurial learning process. Here, the design principles can help create awareness among the teachers and coaches, which is important given that together with the students the teachers and coaches determine the level of complexity and uncertainty that matches the level of the students. In the Climate-KIC Master School, the design principles can help connect the program with preparatory activities and/or courses; this is important because students should be well-prepared before they enter the Climate-KIC Master School, particularly given the highly complex and uncertain nature of the learning process in the program. In addition, entrepreneurial activities - either within the program or outside of the program - can focus on one specific design principle such as the method or room to maneuver, thereby giving students the opportunity to develop certain aspects of wide EE for themselves. In this respect, the design principles can be used at multiple different levels, including the intervention/activity level, the course level, or even on the level of a complete program.

\section{Discussion and Practical Implications}

Consistent with recent reviews regarding EE, this paper departs from the observation that $\mathrm{EE}$ is heavily focused on the desired inputs and outputs of EE, while noting that the process underlying is more important from a wide perspective on EE. Paying more attention to the design of educational programs is essential in order to understand and stimulate the entrepreneurial learning process. This design should stimulate an iterative - even chaotic - process of value creation that allows for learning surprises as outcomes. We argue that designing an EE program that stimulates the value creation learning process in students will allow the students to develop an entrepreneurial mindset and contribute to solving today's complex, pressing issues such as climate change. To facilitate this discussion regarding the design of wide EE for all students, we identified design principles in the published literature and propose these principles as a possible starting point for designing and implementing wide EE.

In presenting these educational design principles, we also hope to contribute to the design and implementation of constructively aligned wide EE programs and interventions. Constructive alignment departs from the notion that objectives, learning activities, and assessments are aligned in high-quality educational 
programs (Biggs, 1996). Kamovich and Foss (2017) studied constructive alignment in EE programs and EE research and concluded that many studies lack constructive alignment; thus, many scholars do not sufficiently report the design of EE practices, and learning activities are often poorly outlined. To increase the quality of EE, more explicit attention should be paid to the design (i.e., the "how") in relation to the inputs (i.e., the learning goals and the students) and outputs (i.e., the learning outcomes and the impact and assessment thereof).

The design principles can be used to: (1) reflect upon existing wide EE programs; (2) develop new wide EE programs; and (3) compare and research wide EE programs. This can be useful at several levels, including the level of specific learning activities, the course level, and the level of the educational program, as well as to elaborate progression models within and across educational levels. An important point here is that there is no "right" or "wrong" approach; rather, the main goal of these principles is to challenge teachers, program developers, and other educational staff to think about the degree of uncertainty and complexity they would like to incorporate into the educational programs, given the specific learning goals and target group. Using this approach, EE programs will be designed more consciously (across educational levels) and will be constructively aligned with respect to their learning outcomes, learning activities, and assessments or impact measures.

In concrete terms, the design principles could be used in practice to reflect upon existing educational programs and for developing new programs that are aimed at stimulating an entrepreneurial mindset in students, integrated within the content of a course. As a starting point, educators can discuss whether the program meets the three prerequisites of wide EE, and if so, how. Next, educators can discuss the eleven design principles with respect to the design of the educational program by asking several questions such as: How is the entrepreneurial process integrated in the course or program?; What are the main characteristics of the tasks the students must deal with either in one course or throughout the program?; and What is the role of the context and peers, the teacher, and external stakeholders in the program? Depending on the level of the students and the learning goals, educators should consciously consider the degree of complexity and uncertainty that they wish to accommodate within a particular course or program. The design principles can be used as a heuristic for educational practitioners to evaluate or improve their current setup and begin to discuss progression models in wide $\mathrm{EE}$ ranging from primary education to higher or even adult education. In addition to educators, the design principles themselves could engage institutional-level stakeholders and policy-makers regarding wide EE programs, thereby opening the door to creating an entrepreneurial mindset in students across educational institutions and levels, encouraging discussions regarding policy guidelines for stimulating wide EE at the national level, for example via the Global Entrepreneurship Monitor (GEM, 
2018). Lastly, the design principles can provide a framework for systematically describing and comparing so-called "good practice studies".

\section{Future Research Agenda}

Consistent with the main hypothesis of this paper, we argue that future research should explicitly study the design of various wide EE programs for various purposes and educational levels before studying the link between the design of wide EE programs and their impact. Both the learning outcomes and the design are currently a black box in EE research (Kamovich \& Foss, 2017), and studies regarding the relationship between design principles and impact are currently lacking (Longva \& Foss, 2018). This line of research should begin by validating the design principles, for example via Delphi studies among teachers. Teachers could then apply the design principles to different levels of wide EE, ranging from primary education through higher education, as well as at the course level, the curricular level, the extracurricular level, and the level of progression models. Such a Delphi study can provide an understanding of what EE should look like at different school levels, as EE is often a school-wide phenomenon and the notion of "entrepreneurship in schools" is often considered the Achilles heel of the entrepreneurial ecosystem (GEM, 2018).

After investigating how the design of wide EE is linked to the aims of wide EE at different educational levels, more systematic and experimental/quasiexperimental studies can be designed in order to study the impact of these design principles and courses that build upon these principles (Longva \& Foss, 2018). Better - and more differentiated - insights into the various designs of EE courses and programs at various educational levels will also pave the way for more differentiated impact studies that go beyond self-efficacy and intention measures by looking at mindset, identity development, intrapreneurship (i.e., entrepreneurship in existing organizations), and entrepreneurial behavior (Longva \& Foss, 2018). In addition, these insights will provide innovation with respect to the ways in which we capture and assess learning outcomes in wide EE. Importantly, when design is used as the starting point, future studies can also examine the kinds of learning surprises that can arise in wide EE programs (Scardamalia et al., 2012), as well as how wide EE programs can provide the opportunity to encourage individual students to exploit the program for their optimal personal development. These questions clearly underscore the need for additional research with respect to how these different kinds of impacts of wide EE can be assessed and valued.

\section{Acknowledgements}

The authors would like to thank Ingrid Christoffels for thinking along with them on the design principles. Also, the authors want to thank the persons involved in using and validating the design principles in practice, and for thinking along with them on the cases. 
In addition, the authors would like to thank the reviewers and Curtis Barrett as proofreader for their positive, constructive feedback.

\section{Declaration of Conflicting Interests}

The author(s) declared no potential conflicts of interest with respect to the research, authorship, and/or publication of this article.

\section{Funding}

The author(s) disclosed receipt of the following financial support for the research, authorship, and/or publication of this article: This work was supported by the Netherlands Initiative for Education Research (NRO) under Project Number (405-17-715).

\section{ORCID iDs}

Yvette Baggen (D) https://orcid.org/0000-0001-6284-3925

Thomas Lans (D) https://orcid.org/0000-0003-4566-5906

\section{References}

Bacigalupo, M., Kampylis, P., Punie, Y., \& Van den Brande, G. (2016). EntreComp: The entrepreneurship competence framework (EUR 27939 EN). Publication Office of the European Union. https://doi.org/10.2791/593884

Blenker, P., Korsgaard, S., Neergaard, H., \& Thrane, C. (2011). The question we care about: Paradigms and progression in entrepreneurship education. Industry \& Higher Education, 25, 417-427. https://doi.org/10.5367/ihe.2011.0065

Bergsteiner, H., Avery, G. C., \& Neumann, R. (2010). Kolb's experiential learning model: Critique from a modelling perspective. Studies in Continuing Education, 32(1), 29-46.

Bernal, A., \& Liñán, F. (2018). The personal dimension of an entrepreneurial competence: An approach from the Spanish basic education context. In A. Fayolle (Ed.), $A$ Research Agenda for Entrepreneurship Education (pp. 262-280). Edward Elgar Publishing.

Biggs, J. (1996). Enhancing teaching through constructive alignment. Higher Education, 32, 347-364.

Brettel, M., Bendig, D., Keller, M., Friederichsen, N., \& Rosenberg, M. (2014). Effectuation in manufacturing: How entrepreneurial decision-making techniques can be used to deal with uncertainty in manufacturing. Procedia CIRP, 17, 611-616. https://doi.org/10.1016/j.procir.2014.03.119

Cohen, D., Hsu, D. K., \& Shinnar, R. S. (2020). Identifying innovative opportunities in the entrepreneurship classroom: A new approach and empirical test. Small Business Economics. Advance online publication. https://doi.org/10.1007/s11187020-00387-z

Cope, J., \& Watts, G. (2000). Learning by doing: An exploration of experience, critical incidents and reflection in entrepreneurial learning. International Journal of Entrepreneurial Behavior \& Research, 6, 104-124. https://doi.org/10.1108/13552550 010346208 
Dew, N., Read, S., Sarasvathy, S. D., \& Wiltbank, R. (2009). Effectual versus predictive logics in entrepreneurial decision-making: Differences between experts and novices. Journal of Business Venturing, 24, 287-309. https://doi.org/10.1016/j.jbusvent.2008.02.002

Donnellon, A., Ollila, S., \& Middleton, K. W. (2014). Constructing entrepreneurial identity in entrepreneurship education. The International Journal of Management Education, 12(3), 490-499. https://doi.org/10.1016/j.ijme.2014.05.004

Fayolle, A., \& Gailly, B. (2008). From craft to science: Teaching models and learning processes in entrepreneurship education. Journal of European Industrial Training, 32, 569-593. https://doi.org/10.1108/03090590810899838

Fiet, J. O. (2001). The theoretical side of teaching entrepreneurship. Journal of Business Venturing, 16, 1-24. https://doi.org/10.1016/S0883-9026(99)00041-5

Garavan, T. N., \& O'Cinneide, B. (1994). Entrepreneurship education and training programmes: A review and evaluation-Part 1. Journal of European Industrial Training, 18, 3-12. https://doi.org/10.1108/03090599410068024

Global Entrepreneurship Monitor. (2018). Global report 2017/2018. Global Entrepreneurship Research Association (GERA). https://www.gemconsortium.org/ report/gem-2017-2018-global-report

Gibb, A. (2002). Creating conducive environments for learning and entrepreneurship. Living with, dealing with, creating and enjoying uncertainty and complexity. Industry \& Higher Education, 16, 135-148. https://doi.org/10.5367/000000002101296234

Grégoire, D. A., \& Cherchem, N. (2020). A structured literature review and suggestions for future effectuation research. Small Business Economics, 54, 621-639. https://doi. org/10.1007/s11187-019-00158-5

Kamovich, U., \& Foss, L. (2017). In search of alignment: A review of impact studies in entrepreneurship education. Education Research International, 2, 1-15. https://doi.org/ $10.1155 / 2017 / 1450102$

Kitching, J., \& Rouse, J. (2020). Contesting effectuation theory: Why it does not explain new venture creation. International Small Business Journal: Researching Entrepreneurship, 38, 1-21. https://doi.org/10.11 77/0266242620904638

Kolb, A. Y., \& Kolb, D. A. 2005. Learning studies and learning spaces: Enhancing experiential learning in higher education. Academy of Management Learning and Education, 4(2), 193-212. https://www.jstor.org/stable/40214287

Kolb, A. Y., \& Kolb, D. A. (2012). Experiential learning theory. In Encyclopedia of the sciences of learning (pp. 1215-1219). Springer.

Kolb, D. A. (1984). Experiential learning. Prentice-Hall.

Lackéus, M. (2015). Entrepreneurship in education: What, why, when, how. Entrepreneurship 360 background paper. OECD-LEED. https:/www.oecd.org/cfe/ leed/BGP_Entrepreneurship-in-Education.pdf

Lackéus, M. (2020). Comparing the impact of three different experiential approaches to entrepreneurship education. International Journal of Entrepreneurial Behavior \& Research, 26, 937-971. https://doi.org/10.1108/IJEBR-04-2018-0236

Lans, T., Baggen, Y., \& Ploum, L. (2018). Towards more synergy in entrepreneurial competence research in entrepreneurship education. In A. Fayolle (Ed.), A research agenda for entrepreneurship education (pp.224-242). Edward Elgar Publishing.

Lans, T., Blok, V., \& Wesselink, R. (2014). Learning apart and together: Towards an integrated competence framework for sustainable entrepreneurship in higher 
education. Journal of Cleaner Production, 62, 37-47. https://doi.org/10.1016/j.jclepro. 2013.03.036

Lilleväli, U., \& Täks, M. (2017). Competence models as a tool for conceptualizing the systematic process of entrepreneurship competence development. Education Research International, 1, 1-16. https://doi.org/10.1155/2017/5160863

Löbler, H. (2006). Learning entrepreneurship from a constructivist perspective. Technology Analysis \& Strategic Management, 18(1), 19-38. https://doi.org/10.1080/ 09537320500520460

Longva, K. K., \& Foss, L. (2018). Measuring impact through experimental design in entrepreneurship education: A literature review and research agenda. Industry and Higher Education, 32(8), 358-374. https://doi.org/10.1177/0950422218804912

Lundqvist, M., Middleton, K. W., \& Nowell, P. (2015). Entrepreneurial identity and role expectations in nascent entrepreneurship. Industry and Higher Education, 29, 327-344. https://doi.org/10.5367/ihe.2015.0272

Man, T. W. Y., Lau, T., \& Chan, K. F. (2002). The competitiveness of small and medium enterprises: Conceptualization with focus on entrepreneurial competencies. Journal of Business Venturing, 17, 123-142. https://doi.org/10.1016/S0883-9026(00)00058-6

Moberg, K., Fosse, H. B., Hoffman, A., \& Junge, M. (2015). Impact of entrepreneurship education in Denmark-2014 (ISBN 978-87-90386-24-5). https://eng.ffe-ye.dk/media/ 785760/impact-of-ee-in-denmark-2014.pdf

Morris, T. H. (2019). Experiential learning-A systematic review and revision of Kolb's model. Interactive Learning Environments, 1-14. https://doi.org/10.1080/10494820. 2019.1570279

Morris, M. H., Webb, J. W., Fu, J., \& Singhal, S. (2013). A competency-based perspective on entrepreneurship education: Conceptual and empirical insights. Journal of Small Business Management, 51, 352-369. https://doi.org/10.1111/jsbm.12023

Nabi, G., Liñán, F., Fayolle, A., Krueger, N., \& Walmsley, A. (2017). The impact of entrepreneurship education in higher education: A systematic review and research agenda. Academy of Management Learning and Education, 16, 277-99. https://doi. org/10.5465/amle.2015.0026

Naia, A., Baptista, R., Januário, C., \& Trigo, V. (2014). A systematization of the literature on entrepreneurship education: Challenges and emerging solutions in the entrepreneurial classroom. Industry and Higher Education, 28, 79-96. https://doi.org/10. 5367/ihe.2014.0196

Obrecht, J. J. (2016). Sustainable entrepreneurship education: A new field for research in step with the 'effectual entrepreneur'. International Journal of Entrepreneurship and Small Business, 29(1), 83-102. https://doi.org/10.1504/ijesb.2016.078029

Perry, J. T., Chandler, G. N., \& Markova, G. (2012). Entrepreneurial effectuation: A review and suggestions for future research. Entrepreneurship Theory and Practice, 36, 837-861.

Ploum, L., Blok, V., Lans, T., \& Omta, O. (2017). Toward a validated competence framework for sustainable entrepreneurship. Organization \& Environment, 31, 113-132. https://doi.org/1086026617697039

Rae, D. (2006). Entrepreneurial learning: A conceptual framework for technology-based enterprise. Technology Analysis \& Strategic Management, 18, 39-56. https://doi.org/ $10.1080 / 09537320500520494$ 
Rasmussen, A., Moberg, K., \& Revsbech, C. (2015). A taxonomy of entrepreneurship education: Perspectives on goals, teaching and evaluation. https://eng.ffe-ye.dk/ media/785766/taxonomy-en.pdf

Read, S., \& Sarasvathy, S. D. (2005). Knowing what to do and doing what you know: Effectuation as a form of entrepreneurial expertise. The Journal of Private Equity, 9, 45-62. https://doi.org/10.3905/jpe.2005.605370

Sarasvathy, S. D. (2001). Causation and effectuation: Toward a theoretical shift from economic inevitability to entrepreneurial contingency. Academy of Management Review, 26(2), 243-263. https://doi.org/10.5465/AMR.2001.4378020

Shane, S. (2000). Prior knowledge and the discovery of entrepreneurial opportunities. Organization Science, 11(4), 448-469.

Scardamalia, M., Bransford, J., Kozma, B., \& Quellmalz, E. (2012). New assessments and environments for knowledge building. In E. Care, P. Griffin, \& M. Wilson (Eds.), Assessment and teaching of 21st century skills (pp. 231-300). Springer.

Schaltegger, S., \& Wagner, M. (2011). Sustainable entrepreneurship and sustainability innovation: Categories and interactions. Business Strategy and the Environment, 20, 222-237. https://doi.org/10.1002/bse.682

Schenck, J., \& Cruickshank, J. (2015). Evolving Kolb: Experiential education in the age of neuroscience. Journal of Experiential Education, 38(1), 73-95. https://doi.org/10. $1177 / 1053825914547153$

Shane, S., \& Venkataraman, S. (2000). The promise of enterpreneurship as a field of research. The Academy of Management Review, 25(1), 217-226. https://doi.org/10. $2307 / 259271$

Smit, A. J. (2018). Complexe problemen oplossen: Design thinking of ontwerpgericht onderzoek [Solving complex problems. Design thinking or design-based research]. OnderwijsInnovatie, 2, 17-24.

Turner, T., \& Gianiodis, P. (2018). Entrepreneurship unleashed: Understanding entrepreneurial education outside of the business school. Journal of Small Business Management, 56(1), 131-149. https://doi.org/10.1111/jsbm.12365

Tynjälä, P. (2013). Toward a 3-P model of workplace learning: A literature review. Vocations and Learning, 6, 11-36. https://doi.org/10.1007/s12186-012-9091-z 